\title{
Pain: the voiceless scream in every haemophilia patient's life
}

Masoume Rambod, Farkhondeh Sharif, * Zahra Molazem, Kate Khair

Pain is a major problem in haemophilia patients' lives. The perspective of pain in such patients is unique and may be different from other chronic illnesses. This qualitative hermeneutic phenomenological study aims to describe and interpret pain experience of haemophilia patients. Participants were selected from a haemophilia clinic affiliated with Shiraz University of Medical Sciences, Shiraz, Iran. Taking the main theme, "pain: the voiceless scream in every moment of haemophilia life", with two subthemes, "a life full of pain" and "describing complex pain quality", data was collected using semi-structured in-depth interviews and field notes, and thematic analysis conducted using van Manen's methodological framework for reflective hermeneutic interpretation. The findings indicated that pain always accompanied the lives of haemophilia patients. Participants experienced acute intense pains, accompanied by bleeding, which were described as "terrible", "severe", "intolerable" and "unbelievable". As joints became damaged over time, participants experienced persistent pain that was "continuous" and "constant". Participants also coped with ever-present pain in immobile joints, described as "intense", "annoying" and "intolerable". This qualitative study shows that pain is present throughout haemophilia patients' lives and that they experience different kinds of pain, demonstrated through various descriptions. By understanding the experience of pain from the perspective of haemophilia patients, nurses and healthcare workers can provide high-quality care focused on their unique needs.

Keywords: adult, experience, haemophilia, pain, qualitative research

Masoume Rambod: PhD Candidate, MS in Nursing, Student Research Committee of Shiraz University of Medical Sciences \& Community Based Psychiatric Care Research Center, Department of Medical Surgical, School of Nursing and Midwifery, Shiraz University of Medical Sciences, Shiraz, Iran.

*Farkhondeh Sharif: PhD, Community Based Psychiatric Care Research Center, Department of Mental Health and Psychiatric Nursing, School of Nursing and Midwifery, Shiraz University of Medical Sciences, Shiraz, Iran. Email: fsharif@sums.ac.ir

Zahra Molazem: PhD, Community Based Psychiatric Care Research Center Department of Medical Surgical, School of Nursing and Midwifery, Shiraz University of Medical Sciences, Shiraz, Iran.

Kate Khair: Consultant Nurse Haemophilia, Great Ormond Street Hospital for Children NHS Foundation Trust, London WC1N 3JH and Visiting Professor of Health and Social Care, London South Bank University, London, UK.

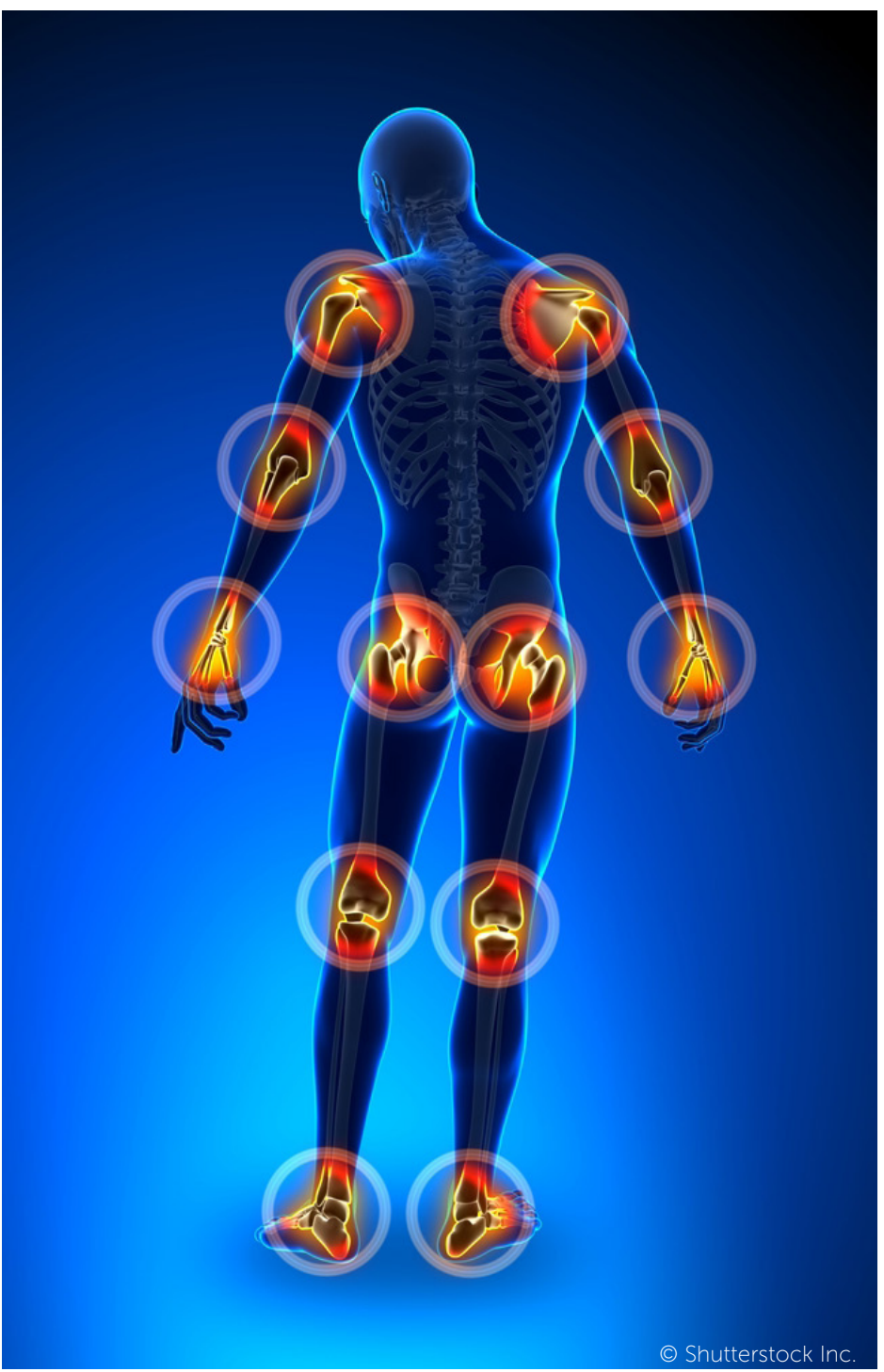

Pain is a persistent problem in haemophilia patients' lives due to joint bleeding [1]. Pain acts as a warning sign and protects the affected body area from further damage [2]. Haemophilia patients normally experience acute, recurrent, and chronic pain [3]. Studies have shown that $15 \%$ to $>50 \%$ of adults with severe haemophilia suffered from chronic pain [4-6]. A study by Gringeri et al indicated that $71 \%$ of patients with severe haemophilia had 'some or moderate pain', with 4\% reported 'extreme' pain [7]; while a recent study by Kalnins et al reported that more than three quarters of haemophilia subjects experienced episodes of pain [8]. Chronic and acute pain may affect the lives 


\begin{tabular}{|c|c|}
\hline \multicolumn{1}{|c|}{\begin{tabular}{c} 
Question \\
\hline 1
\end{tabular}} & $\begin{array}{c}\text { Tell me about your pain? } \\
\text { patient's life? }\end{array}$ \\
\hline 3 & What is the meaning of pain in a haemophilia \\
\hline 4 & $\begin{array}{c}\text { When you hear the word "pain in haemophilia", what } \\
\text { did you think about or what comes to your mind? }\end{array}$ \\
\hline 5 & Tell me a story of when you had pain \\
\hline
\end{tabular}

Table 1: Interview guide

of haemophilia patients'; joint stiffness, loss of range of motion, and decreased function are also associated with chronic synovitis and advanced arthropathy [9].

Despite its high prevalence and the complications associated with pain in haemophilia patients, no diseasespecific definitions of pain or evidence-based guidelines regarding its assessment and management are available [5]. Witkop et al indicate that the most frequently reported words for acute pain were 'throbbing, aching, sharp, tender, and miserable', while for persistent pain, they were 'aching, nagging, tiring, sharp, and tender' [10]. Van Genderenet al also describe patients reporting pain as 'nagging', 'stiff', 'annoying' and 'moderate' [11].

Although there have not been many studies of pain in adult patients with haemophilia in recent years, those undertaken have used quantitative study design $[4,10,12]$. However, quantitative studies do not adequately demonstrate the pain experience of haemophilia patients. Moreover, so far, no qualitative studies have been conducted on pain experience in this population, and the qualitative description of pain in haemophilia patients is therefore not clear. Lack of understanding of the meaning of pain in haemophilia patients is a barrier to appropriate clinical care and clinical research.

This qualitative hermeneutic phenomenological study aims to describe and interpret pain experience among haemophilia patients, based on answers to the question "What is the haemophilia patients' experience of living with pain?"

\section{Methods}

\section{Study settings and samples}

The study was conducted in the haemophilia centre at Dastgheib Hospital, which is affiliated with Shiraz University of Medical Sciences, Shiraz, Iran. The target population consisted of mild, moderate and severe haemophilia patients (A or B), aged 18 years old or above, who were Persianspeaking, had known experience with the phenomenon under study (haemophilia pain), had been diagnosed with haemophilia at least 6 months previously, were cognitively able to give information, and were alert and oriented.

\begin{tabular}{|c|c|}
\hline Variables & n (\%) \\
\hline Age mean (SD) & $28.42(5.65)$ \\
\hline $\begin{array}{l}\text { Gender } \\
\text { Male } \\
\text { Female }\end{array}$ & $\begin{array}{c}1(7.14) \\
13(92.85)\end{array}$ \\
\hline $\begin{array}{l}\text { Treatment regimen } \\
\text { Prophylaxis } \\
\text { On-demand }\end{array}$ & $\begin{array}{c}0(0.0) \\
14(100)\end{array}$ \\
\hline $\begin{array}{c}\text { Haemophilia severity } \\
\text { Severe } \\
\text { Moderate } \\
\text { Mild }\end{array}$ & $\begin{array}{l}9(64.28) \\
2(14.28) \\
3(21.42)\end{array}$ \\
\hline $\begin{array}{c}\text { Haemophilia type } \\
\text { A } \\
\text { B }\end{array}$ & $\begin{array}{c}13(92.85) \\
1(7.14)\end{array}$ \\
\hline $\begin{array}{c}\text { Painful regions } \\
\text { Knee } \\
\text { Ankle } \\
\text { Elbow } \\
\text { Femur } \\
\text { Wrist } \\
\text { Shoulder } \\
\text { Spine }\end{array}$ & $\begin{array}{l}11(78.58) \\
4(28.57) \\
5(35.71) \\
2(14.29) \\
1(7.15) \\
1(7.15) \\
1(7.15)\end{array}$ \\
\hline $\begin{array}{c}\text { Number of painful joints } \\
1 \\
2 \\
3 \\
4 \\
5+\end{array}$ & $\begin{array}{c}3(21.43) \\
5(35.71) \\
3(21.43) \\
0(0.0) \\
3(21.43)\end{array}$ \\
\hline $\begin{array}{l}\text { Arthropathy } \\
\text { Yes } \\
\text { No }\end{array}$ & $\begin{array}{c}12(85.71) \\
2(14.29)\end{array}$ \\
\hline
\end{tabular}

\section{Table 2: Socio-demographic characteristics of study} participants

Subjects diagnosed with cognitive impairments and those suffering from untreated mental illness and other genetic diseases were excluded from the study.

Participants were initially recruited using convenience and purposeful sampling. Non-probability snowball sampling was also used, whereby early sample members were asked to refer other patients who met the eligibility criteria.

\section{Data collection and analysis}

Data collection was performed from March 2014 to April 2015 using a socio-demographic characteristics form, interviewing and field notes. Semi-structured, in-depth interviews using question probes were employed to elicit the lived experience of pain in haemophilia patients, starting with the question "What has been your experience of pain while living with haemophilia?" The full list of questions is presented in Table 1. Interviews were conducted in a quiet, private room in the haemophilia ward at Dastgheib Hospital, and lasted for approximately 30-60 minutes. All interviews 
were digitally audio-taped and transcribed for use in data analysis; the transcripts were imported into the MAX.QDA qualitative software package (2010). The researcher's field notes on conversations with the participants were used as a secondary data source.

Data analysis started with the first interview and was performed simultaneously with data collection. Analysis was conducted using van Manen's (1990) six-step methodological framework for reflective hermeneutic interpretation and involved:

- Turning to a phenomenon which seriously interests and commits us to the world;

- Investigating experience as we live it rather than as we conceptualise it;

- Reflecting on the essential themes which characterise the phenomenon;

- Describing the phenomenon through the art of writing and rewriting;

- Maintaining a strong and oriented pedagogical relation to the phenomenon;

- Balancing the research context by considering parts and the whole [13].

The essence and meaning of the pain phenomenon were identified using thematic analysis guided by van Manen's 'meaning-giving' approach [14]. The researchers made use of holistic sententious, selective/highlighting, and detailed/ line-by-line analysis techniques. Conducting thematic analysis in this way enabled the extraction of themes, which started broad and then became more specific [14].

\section{Ethical considerations}

The study was approved by the Ethics Committee of Shiraz University of Medical Sciences. The study's objectives, interviewing procedures, and the participants' involvement, benefits, risks, confidentiality and anonymity were explained in writing in an informed consent form. Consent was also gained for the digital audio-taping of the interviews.

\section{Rigour}

The trustworthiness of the data collected was approved using Lincoln and Guba's (1985) criteria of credibility, transferability, dependability and confirmability [15]. Purposeful sampling, referral adequacy, peer debriefing and member checks were performed in order to increase credibility; an audit trail was used to enhance dependability and confirmability. In order to facilitate transferability, purposeful sampling was used and participants were selected from different areas of Fars Province.

\section{Results}

\section{Socio-demographic characteristics}

Of 390 haemophilia patients identified, 14 adult haemophilia patients participated in this study. The participants' sociodemographic characteristics are presented in Table 2. The mean age of the participants was $28.42(S D=5.65)$ years; 13 subjects were male and one was female. The majority of participants had severe (64.2\%) type A (92.8\%) haemophilia.

Pain: the voiceless scream in every moment of haemophilia patients' lives

Throughout the process of analysis, the main theme was "pain: the voiceless scream in every moment of haemophilia patients' lives". There were two subthemes: "a life full of pain" and "describing complex pain quality". These subthemes are described in detail as follows.

\section{A life full of pain}

Pain accompanies the lives of haemophilia patients from childhood, and in some cases even from birth. Most of the participants in the study experienced pain throughout the stages of growth and development, and at any hour of the day. Only two participants, who were born after factor became available in Iran, reported that their pain started from adolescence and has continued. All participants maintained that pain occurs in various parts of the body (e.g. knee, ankle, shoulder, femur, elbow, wrist) and, moreover, that the pain fluctuates.

Regarding the tangibility of pain in life, Participant 8 stated, "Pain is not a strange thing. It's something we've had since childhood. We have it in our lives."

Participant 14 referred to consistency of pain in his life: "Always, I constantly have pain. Believe me, whenever I can remember, I had pain. I've suffered from pain from childhood. Knee pain. Haemophilia is a pain, a pain that is always with you ... These pains are the thing that will not be finished. It is with us until the end of life."

Concerning the onset of pain at any time and the unpredictable and irregular characteristics of pain, Participant 8 said, "The pain suddenly starts at night or midnight ... Last week, I was asleep. When I got up in the morning, I felt that I had elbow pain. You know, I had no pain when I slept at night or on the previous day."

Participants remembered every pain during their growth and developmental stages. Participant 7 stated, "Many areas of my body, such as elbows and knees, have been painful since childhood ... I also had pain in middle school; I remember that my ankle bled so much. I had pain in this area and I went to school with a cane... When I was a little older, my knees hurt. I frequently went to the hospital and came back home ... I have had pain from childhood up to now."

\section{Describing complex pain quality}

Participants described their pain based on frequency or duration (acute, persistent and ever-present, related to the immobility of joints). According to their descriptions, pain intensity ranged from mild ("aching", "tolerable") to extremely intense pain ("terrible", "severe", "intolerable" and "unbelievable"). The quality of acute pain related to bleeding 
was described as intense; at first, it was "hot" and with "tingling", and it gradually increased until it was "terrible", "severe", "intolerable", "unbelievable", and "worse than heart attack pain".

Describing intense knee pain related to bleeding during adolescence, Participant 9 stated, "If you have experienced joint pain, it's too bad. It was unbelievable; it was worse than heart pain or everything worse. I twisted like a snake due to the severity of pain. The pain was intense. I was crying from the pain at nights."

Similarly, regarding recent intense pain accompanied by bleeding, Participant 3 maintained, "When bleeding occurs, the pain is so much that I want to scream." Other participants reported acute pain related to bleeding as "a fire that is flaring gradually", "bursting of the joint", "being shot", "a feeling of imminent explosion in the joint", and "pain within the limbs". They also stated that the intensity of pain in childhood, when factor was not available, led to a tendency to scream, being impatient, being restless, and crying throughout the night.

Concerning the quality of pain related to bleeding when factor was not available, Participant 13 said, "It [the pain] was terrible. It was similar to an explosion ... Because the swelling has gradually increased and bleeding is happening under the skin, every hour [the pain in] that area is triggered and you are under pressure ... It seems that it's bursting inside." Participant 11 described pain in this circumstance as being "like a man who has been shot with ten bullets in his leg; like being shot, or worse ... I couldn't put my feet on the ground."

The second description of frequency or duration of pain was persistent pain that occurred in previous bleeding sites as a result of damage to joints. Participants described this pain as mild to severe, "continuous", "constant", "persistent", and "infinite pain" that was insufficiently treated.

Participant 7 stated, "I always have pain during walking, persistent and tolerable pain in my ankle and foot. So many years it has remained with me, for years."

Describing continuous, constant pain, Participant 1, who had bleeding in the right knee three years previously and joint damage, said, "My knee hasn't returned to normal; I still have problems with it. I mean, if I want to run, I'll have pain. At night, when I want to sleep, it has pain. When I wake up, my joint has stiffness and pain ... It has pain all the time."

Participant 7 also described the intense, persistent pain in his damaged left elbow: "I have pain; I always have persistent pain, continuously. Now that I am speaking with you, now I have pain. I feel sharp pain from my elbow to my fingertips."

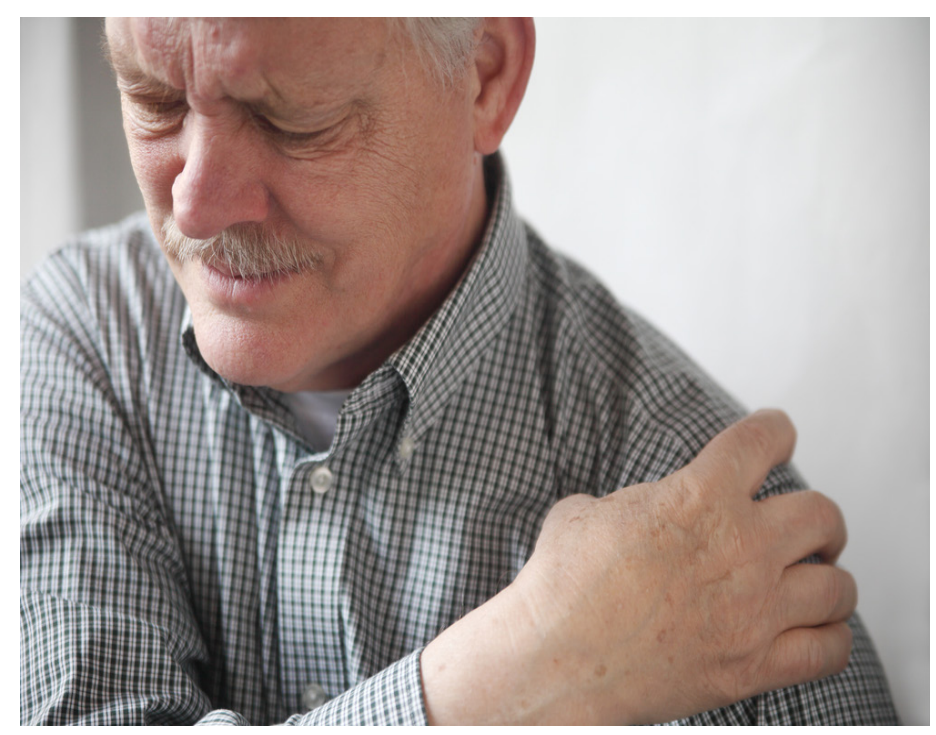

(C) Shutterstock Inc.

The third description of frequency or duration of pain was the pain that was ever-present after short- or long-term immobility of joints. This intense, annoying and intolerable pain occurred after rest and immobility, and gradually relieved with mobilisation of the limbs. Participants explained this pain as being "like putting a bone in the foot", "dislodging of something from the bone", and "immediate, short-term, and sharp pain".

In this respect, Participant 8 maintained, "When I rest for only for four to five hours, my joints become fixed and painful and if I want to move I have severe pain ... When I put my feet on the ground, I had pain, intolerable pain. There is much pain. I need at least ten minutes Ito be able to start moving]. I have to move my feet slowly so that they return to their original state. My pain slowly decreases and the joint becomes smooth, and then I have no pain."

Participants revealed that pain before the availability of factor was prolonged and intense. Participant 7 recounted, "At night or midnight, pain was started... Because those times there was no factor, I had to go to the hospital the next morning. So, we had to use cryo [cryoprecipitate] that needs time to be prepared. So my pain was there for a long time."

Once factor became available, the duration and severity of pain decreased. In fact, factor was considered as pain relief or analgesic. Moreover, participants maintained that, when in acute pain, they adhere to treatment regimens such as infusion of factor because it provides pain relief, and prevents pain and bleeding complications. In this respect, Participant 13 stated, "As the pain started, I got the factor. Then, I did my daily routine. That day, the pain was intangible. I didn't have any problems. If I use it [factor] soon, we can solve the problem quickly, so later it does not have bad effects on the joint and I will not have limited mobility and severe pain." 


\section{Discussion}

In response to the question "What is the haemophilia patients' experience of living with pain?" the results of this study indicate that pain is a common component of the lives of haemophilia patients.

Participants in the study had experienced pain during growth and developmental stages, from childhood and throughout adult life, a finding which is consistent with other recent studies. Pain is a known complication in haemophilia, often starting at a young age as a result of joint bleeding [3]. Kodra et al report that pain is present throughout a haemophilia patient's life, and that approximately $75 \%$ of adult patients with haemophilia had quality of life problems associated with pain and discomfort [16]. In the study by Kalnins et al, $86 \%$ of haemophilia subjects experienced episodes of pain [8].

In the current study, pain occurred in various parts of the body (knee, elbow, ankle, shoulder, wrist, femur, etc.). Previous research has indicated that more than $50 \%$ of haemophilia patients had painful joints [6], and that joint pain was the most severe type of pain (92\%) [8].

Participants in our study described the acute pain related to bleeding as "terrible", "severe", "intolerable", and "unbelievable"; like "a flaring fire", "bursting", "being shot" and "imminent explosion"; and led to a tendency to scream, impatience and restlessness. Although this has not been explained in any qualitative studies, Witkop et al showed that the most frequently-reported words for acute pain in haemophilia patients were "throbbing", "aching", "sharp", "tender" and "miserable" [4,10]. In research by Hilberg et al, pain was most commonly described as "sharp", followed by "tugging", "pressing", "hot" and "dull" [12].

In the present study, participants repeatedly revealed that they had persistent pain. A recent report on the HERO Study (Haemophilia Experiences, Results and Opportunities) stated that $38 \%$ of participants with haemophilia A and $42 \%$ of those with haemophilia B indicated chronic pain [17]. In another recent study by McLaughlin et al, one third of adolescents and young adults with moderate or severe haemophilia showed chronic pain [18]. Moreover, in a European study of 6,000 haemophilia patients, 35\% of adults and $8 \%$ of children had chronic pain [5]. Chronic or persistent pain is a pervasive problem in haemophilia patients' lives [1].

Persistent pain was defined in the current study as pain that is continuous and constant. In some participants, this kind of pain was described as sharp, whilst others reported it as being tolerable. Furthermore, our study results demonstrated that the severity of persistent pain fluctuated and was insufficiently treated by analgesia, rest, ice, compression, elevation and factor. Persistent pain related to previous bleeding may always be present and may not diminish completely, even if sufficient haemostasis is achieved with factor administration [2].

One type of pain described by participants was the everpresent pain caused by immobility of joints. This was described as intense, annoying and intolerable. A quality of life analysis of data collected in the HERO Study indicated that $50 \%$ of adults with all severities of haemophilia experienced constant pain [19].

The findings of our study indicated that factor reduced the severity of pain. Thus, participants adhered to their treatment regimen because they recognised that factor acted as an analgesic and prevented pain and bleeding complications. A study of children and adolescents with bleeding disorders in three centres in London and Iran indicated that over $79 \%$ of participants used factor for pain relief. Moreover, $100 \%$ of Iranian participants injected factor as a strategy for pain relief [20]. McLaughlin et al reported that better adherence to a prescribed treatment regimen is related to the reduction of chronic pain among adolescents and young adults with moderate or severe haemophilia [18]. Clotting factor is the key to effective haemophilia management [21]. Consistent with our study, a qualitative study of health-related quality of life in people with haemophilia by Beeton at al reported that the availability of factor reduced the incidence and severity of bleeding episodes, also giving patients freedom to live a normal life, enabling them to make plans and look to the future [22].

Overall, this qualitative study provided useful information about the nuances of pain and quality of pain in adult haemophilia patients. Nurses and healthcare workers enquire about and listen carefully to patients' stories about their pain. Only by understanding the pain experience of haemophilia patients from their own perspective can nurses provide high-quality care focused on patients' unique needs. Moreover, they can reduce the complications of haemophilia and pain over time by providing patients with support, especially during periods of acute bleeding/pain. Further research is required to explore the lived experience of coping with pain coping, as well as the psychosocial and physical challenges of pain experienced by haemophilia patients.

\section{Limitations}

As with other qualitative studies, this study had some limitations. These limitations consisted of generalisation of the results and a small sample size. Future research in this area should therefore examine whether the findings obtained from Iranian haemophilia participants are applicable to the wider haemophilia population. Participants' access to treatment in the past may also have a bearing on the results of this study. 


\section{Conclusion}

The findings of this qualitative study indicate that pain is a common problem in the lives of haemophilia patients. Acute intense pain that is "terrible", "severe", "intolerable" and "unbelievable" occurred after bleeding. As joints became damaged, patients experience persistent pain, which was continuous and constant. Additionally, they must cope with the ever-present pain of immobile joints, described "intense", "annoying" and "intolerable". Thus, nurses and healthcare providers must strive to help the patients with haemophilia deal with pain, as one of the greatest challenges of living with haemophilia, to improve their quality of life.

\section{Ethical approval}

The study was approved by the Ethics Committee of Shiraz University of Medical Sciences, Shiraz, Iran (937081).

\section{Acknowledgments}

This study was a part of Masoume Rambod's PhD dissertation, approved and financially supported by the Vice-Chancellor of Shiraz University of Medical Sciences, Shiraz, Iran (No. 93-7081). Special thanks go to Shiraz University of Medical Sciences and the healthcare providers from the haemophilia clinic for their assistance. The authors also wish to acknowledge the 14 study participants. The authors would like to thank Ms. A. Keivanshekouh at the Research Improvement Centre of Shiraz University of Medical Sciences for improving the use of English in the manuscript.

\section{Author contributions}

The study was designed by MR, FS, ZM and KK. The interviews were undertaken by MR. The data was analysed by MR and FS. The paper was written by MR, FS, ZM and KK. All of the authors critically reviewed the early drafts of the paper and agreed the final version.

\section{Disclosures}

The authors have advised that there are no interests that might be perceived as posing a conflict or bias.

This is an Open Access article distributed under the terms of the Creative Commons Attribution License (http://creativecommons.org/ licenses/by/2.0), which permits unrestricted use, distribution, and reproduction in any medium, provided the original work is properly cited.

\section{References}

1. Young G, Tachdjian R, Baumann K, Panopoulos G. Comprehensive management of chronic pain in haemophilia. Haemophilia 2014; 20: 113-20.

2. Humphries TJ, Kessler CM. The challenge of pain evaluation in haemophilia: can pain evaluation and quantification be improved by using pain instruments from other clinical situations? Haemophilia 2013; 19: 181-7.

3. Pipe SW, Valentino LA. Optimizing outcomes for patients with severe haemophilia A. Haemophilia 2007; 13 Suppl 4: 1-16.

4. Witkop M, Lambing A, Divine G, Kachalsky E, Rushlow D, Dinnen J. A national study of pain in the bleeding disorders community: a description of haemophilia pain. Haemophilia 2012; 18: e115-9.

5. Holstein K, Klamroth $\mathrm{R}$, Richards $\mathrm{M}$, et al. Pain management in patients with haemophilia: a European survey. Haemophilia 2012; 18: 743-52.

6. Riley RR, Witkop M, Hellman E, Akins S. Assessment and management of pain in haemophilia patients. Haemophilia 2011; 17: 839-45.

7. Gringeri A, Mantovani LG, Scalone L, Mannucci PM, Group CS. Cost of care and quality of life for patients with haemophilia complicated by inhibitors: the COCIS Study Group. Blood 2003; 102: 2358-63.

8. Kalnins W, Schelle G, Jost K, Eberl W, Tiede A. Pain therapy in haemophilia in Germany. patient survey (BESTH study). Hamostaseologie 2015; 35: 167-73.

9. Raffini L, Manno C. Modern management of haemophilic arthropathy. Br J Haematol 2007; 136: 777-87.

10. Witkop M, Lambing A, Kachalsky E, Divine G, Rushlow D, Dinnen J. Assessment of acute and persistent pain management in patients with haemophilia. Haemophilia 2011; 17: 612-9.

11. van Genderen FR, Fischer K, Heijnen $L$, et al. Pain and functional limitations in patients with severe haemophilia. Haemophilia 2006; 12: 147-53.

12. Hilberg T, Czepa D, Freialdenhoven D, Boettger MK. Joint pain in people with haemophilia depends on joint status. Pain 2011; 152: 2029-35.

13. van Manen M. Researching lived experience: Human science for an action sensitive pedagogy. 1990. New York, NY: State University of New York Press.

14. van Manen M. Phenomenology of practice: meaning-giving methods in phenomenological research and writing. 2014. Walnut Creek, California: Left Coast Press.

15. Lincoln Y, Guba E. Naturalistic inquiry. 1985. Beverly Hills: Ca: Sage. 16. Kodra $Y$, Cavazza M, Schieppati $A$, et al. The social burden and quality of life of patients with haemophilia in Italy. Blood Transfusion= Trasfusione del Sangue 2014; 12 Suppl 3: s567-75.

17. Forsyth AL, Gregory M, Nugent D, et al. Haemophilia Experiences, Results and Opportunities (HERO) Study: survey methodology and population demographics. Haemophilia 2014; 20: 44-51.

18. McLaughlin JM, Witkop ML, Lambing A, Anderson TL, Munn J, Tortella $B$. Better adherence to prescribed treatment regimen is related to less chronic pain among adolescents and young adults with moderate or severe haemophilia. Haemophilia 2014; 20: 506-12.

19. Garrido C, Ramirez S, Forsyth A, Iorio A. Quality of life (QOL) and well-being of haemophilia patients and parents managing haemophilia: HERO study analysis. Haemophilia 2012; 18: 177.

20. Rambod M, Forsyth K, Sharif F, Khair K. Assessment and management of pain in children and adolescents with bleeding disorders: a crosssectional study from three haemophilia centres. Haemophilia 2015; accepted article.

21. Elander J. A review of evidence about behavioural and psychological aspects of chronic joint pain among people with haemophilia. Haemophilia 2014; 20: 168-75.

22. Beeton K, Neal D, Lee C. An exploration of health-related quality of life in adults with haemophilia--a qualitative perspective. Haemophilia 2005; 11: 123-32. 